\title{
HEALTH LITERACY: KNOWLEDGE AND EXPERIENCE AMONG SENIOR STUDENTS IN A NURSING COLLEGE
}

\author{
Trixia S. Maduramente ${ }^{1}$, Jeric D. Orendez ${ }^{2}$, Judelle A. Saculo ${ }^{3}$, Angela Louise A. Trinidad ${ }^{4}$, Ryan \\ Michael F. Oducado ${ }^{4 *}$ \\ West Visayas State University of Philippines \\ Email* : rmoducado@wvsu.edu.ph
}

\begin{abstract}
Introduction: Training and education on health literacy must start in the undergraduate nursing program. While nursing schools include health education courses and provide opportunities for nursing students to give healthcare information to individuals in various healthcare settings, there is a dearth of empirical evidence on health literacy in the Philippines. The purpose of this study was to examine the health literacy knowledge and experience of senior nursing students in a College of Nursing in Iloilo City, Philippines. Methods: This study utilized a descriptive crosssectional research design with 160 senior nursing students as participants. Data were gathered using Cormier's (2006) Health Literacy Knowledge and Experience Survey (HL-KES) questionnaire. Descriptive statistical tools, $t$ test, ANOVA and Pearson's $r$ were used to analyze the data. Results: Results revealed that majority of senior nursing students had limited health literacy knowledge $(M=13.19)$ and had moderate health literacy experience $(M=2.50)$. No significant differences were found in the knowledge and experience according to sex ( $p>.05)$ as well in grade in Health Education course ( $p>.05)$. Knowledge of health literacy was not significantly related to health literacy experience $(p>.05)$. Conclusions: Health literacy must be given greater emphasis in the undergraduate nursing curriculum. Nursing schools must pay more attention to devising measures in improving nursing students' health literacy competencies.
\end{abstract}

Keywords: health education; health literacy; nursing education; nursing students; philippines

\section{INTRODUCTION}

Health literacy is a concern of everyone involved in health care (Institute of Medicine, 2004). Health literacy is the degree to which individuals have the capacity to obtain, process and understand basic health information and services needed to make appropriate health decisions (United States Department of Health and Human Services, 2000; Agency for Healthcare Research and Quality, 2016). Skills on health literacy are needed in activities such as information exchanges and discussions related to health and in reading health information (Institute of Medicine, 2004). Besides, health literacy can be an instrument for providing equal and culturally competent care across the nation (Sullivan, 2015).

Low health literacy is a significant present-day public health problem (Cornett, 2009). Limited health literacy has a significant impact on patients' health outcomes (SandJecklin et al., 2010; McCleary-Jones, 2012).
Patients with low health literacy are more likely to visit an emergency room, have higher rates of hospitalization, worse health status, higher mortality rates and are less likely to follow treatment plans (Sand-Jecklin et al., 2010; Griffey, Kennedy et al., 2014; Centers for Disease Control and Prevention, 2016). In the Philippines, it is disturbing to note that despite the country's high literacy rate, it appears that this does not always translate to high health literacy (Agosto et al., 2018).

Healthcare professionals, nurses, including nursing students are primary movers for addressing the problems regarding low health literacy. Nursing students must be educated and trained well on the assessment and application of health literacy strategies (Sand-Jecklin et al., 2010; Williamson \& Chopak-Foss, 2015; Kennard, 2017). Preparing nurses to address problems associated with low health literacy is vital because of their patient education role (Torres \& Nichols 2014). However, while health education is included in the nursing curriculum, 
there is no sufficient evidence backing that nursing schools are preparing nursing students with sufficient knowledge and experience regarding health literacy (Cormier, 2006). Currently, there are no standards for the inclusion of trainings on health literacy in the undergraduate nursing curriculum (Borrero, 2016).

There is a notion that health professionals have higher health literacy (Budhathoki et al., 2019). Still, nursing seems to be a discipline that is most missing in health literacy knowledge and awareness (Kennard, 2016). Several studies conducted in countries like the United States of America (Cormier, 2006; Cormier \& Kotrlik, 2009; Clark, 2009; Macabasco-O'Connell \& FryBowers, 2011; Cafiero, 2013); Georgia (Knight, 2011; Williamson \& Chopak-Foss, 2015), Lithuania (Sukys et al., 2017), Australia (Mullan et al., 2017), South Africa (Mibei \& Daniels, 2019), Iran (Nesari, 2017) and China (Zhang et al., 2016) yielding the same results of having low health literacy knowledge, strategies and experience among nursing students, nurses and healthcare professionals. Locally, a local terminal assessment study found that graduating nursing students' ranked lowest in the area of health education (Belo-Delariarte et al., 2018).

Based on studies mentioned, health literacy is indeed a significant concern that requires attention. It does not only involve the patients but the healthcare members as well. More specifically, health literacy competence is required among nurses and soon to be professional nurses, since they are responsible in the provision of health information, education, and preventive care. Despite numerous studies conducted on health literacy, to the researchers' knowledge, there is a paucity of published information regarding health literacy among Southeast Asian countries, particularly in the Philippines, that needs to be explored and investigated. This study aimed to examine the level of health literacy knowledge and health literacy experience among senior nursing students in a College of Nursing in Iloilo City, Philippines and whether significant differences existed in nursing students' health literacy knowledge and health literacy experience when grouped according to sex and grade in Health Education course.

\section{METHODS}

This study utilized a descriptive crosssectional research design. All one hundred sixty (160) senior nursing students in a College of Nursing in Iloilo City, Philippines participated in this research. $27(16.9 \%)$ were males, and 133 $(83.1 \%)$ were females.

Cormier's (2006) Health Literacy Knowledge and Experience Survey (HL-KES) was used to gather data. Permission to use the HL-KES was secured and granted by the author. To check for cultural equivalency, the instrument was subjected to content validation by local experts, pilot, and reliability testing. Part I was composed of 29-item multiple choice questions on Health Literacy Knowledge. All knowledge items from the original survey were adopted. A score of one (1) point was given to every correct answer. Low health literacy knowledge means that the participant answered correctly less than $50 \%$ of the total items in the test.

Part II, the Health Literacy Experience, was used to assess how often nursing students participated in learning activities related to health literacy and patient teaching. All nine (9) items from Cormier's Health Literacy Experience survey were included. Additional four (4) items were based on the work of Knight (2011). On this part of the survey, the participants were asked to answer in a 4-Point Likert scale format with responses ranging from " $1=$ almost never" to " 4 = almost always". Higher scores indicated more health literacy experience. The following scale of mean was used to interpret that data: $1.00-1.99=$ low, $2.00-2.99=$ moderate, $3.00-4.00=$ high health literacy experience.

The participants were also asked to indicate their sex on the upper portion of the first part of the questionnaire. Moreover, grades in Health Education course were taken from the University Registrar after participants' consent were obtained. Grade in Health Education course was expressed in 1.0 to 5.0 (highest is 1.0).

During the pilot survey, 35 students in another College of Nursing in the City evaluated the instrument in terms of readability, clarity, length, and level of difficulty of the items. The HL-KES has an overall Cronbach's alpha of .82 (Cormier, 2006). Other studies reported $\alpha=.81$ (Knight, 2011) and $\alpha=.69$ (Cafiero, 2013). For 
this study, the reliability coefficient for the experience part of the survey was $\alpha=.84$.

Relevant permissions to conduct the study were secured. Before the distribution of the survey questionnaires, the researchers gave a brief description of the purpose of the study, guaranteed students' anonymity, and reassured that completing the HL-KES would have no influence on any of their course grades. Signed informed consent forms were obtained from the participants to indicate their voluntary involvement in the study. Nursing students were given 60 minutes to answer the research instrument. Students answered the survey inside their classroom. After answering, the instruments were retrieved by the researchers and were checked for data entry completeness.

For statistical data analysis, the SPSS software package version 23 was utilized. Frequency count, percentage, mean, standard deviation (SD), and rank were used to describe the data. The t-test and ANOVA were employed to determine significant differences while Pearson's $r$ was performed to determine relationship between variables. The result was significant if the alpha level was below .05.

The Declaration of Helsinki (World Medical Association, 2001) and the National Ethical Guidelines for Health and Health-Related Research (Philippine Health Research Ethics Board, 2017) served as guides to the researchers in the ethical conduct of the study. The technical and ethical soundness of the research was reviewed by the thesis committee of the College.

\section{RESULTS}

Table 1 shows that the majority $(68.8 \%)$ of the senior nursing students had a low level of knowledge about health literacy with a mean score of 13.19 over 29. Low health literacy means that nursing students have inadequate knowledge about health literacy obtaining a score of less than $50 \%$ of correct answers in the Health Literacy Knowledge Part of the questionnaire. Moreover, it can be gleaned in Table 1 that most (79.4\%) of the senior nursing students had a moderate health literacy experience with a mean score of 2.50 . This means that senior nursing students normally engage or participate in various health literacy activities.
Table 2 shows that almost all of the senior nursing students knew that the best approach to initiating a health literacy screening with a patient made by the nurse is making sure to explain things in a way that is easy for patients to understand and by letting them read some words (94.4\%) and that nurses should keep in mind that individuals with low health literacy levels have difficulty applying healthcare information to their health situation (90\%). Majority of them knew that patients with low health literacy skills are often diagnosed late and have fewer treatment options than those with adequate health literacy skills $(88.8 \%)$, that an individual with functional health literacy will be able to read, comprehend, and actively participate in decisions concerning healthcare $(88.8 \%)$, and that recommendations for developing written healthcare materials include presenting information in the form of a conversation $(81.9 \%)$.

On the other hand, senior nursing students had limited knowledge of items related to guidelines for presenting written health care information and health literacy screening. Only one-fourth of senior nursing students knew that individuals who have low health literacy skills may not admit that they have difficulty reading $(25.6 \%)$ and that the best way to ensure that a breast cancer prevention brochure is culturally appropriate is to include community members in 
Table 3. Proportion of Almost Always Responses on Health Literacy Experience

\begin{tabular}{|c|c|c|}
\hline How often... & $f$ & $\%$ \\
\hline \multirow{2}{*}{$\begin{array}{l}\text { was health literacy emphasized in your nursing curriculum? } \\
\text { did you assess what the patient already knows about his/her illness or injury prior } \\
\text { to teaching? }\end{array}$} & 56 & 35 \\
\hline & 43 & 26.9 \\
\hline $\begin{array}{l}\text { did you alter your teaching methods based upon the patient's health literacy status } \\
\text { whether formally assessed or not? }\end{array}$ & 28 & 17.5 \\
\hline $\begin{array}{l}\text { did you use written materials to provide healthcare information to an individual or } \\
\text { community group? }\end{array}$ & 26 & 16.3 \\
\hline $\begin{array}{l}\text { did you evaluate the use of illustrations in written healthcare materials before using } \\
\text { them for patient teaching? }\end{array}$ & 25 & 15.6 \\
\hline \multirow{2}{*}{$\begin{array}{l}\text { did you assess the health literacy level of your patient? } \\
\text { did you evaluate the reading level of written healthcare materials before using them } \\
\text { for patient teaching? }\end{array}$} & 24 & 15 \\
\hline & 19 & 11.9 \\
\hline $\begin{array}{l}\text { did you use computer software to provide healthcare information to an individual } \\
\text { or community group? }\end{array}$ & 17 & 10.6 \\
\hline \multirow{2}{*}{$\begin{array}{l}\text { did you evaluate the cultural appropriateness of healthcare materials, including } \\
\text { written handouts, videos, audiotapes, before using them for patient teaching? } \\
\text { did you use videotapes to provide healthcare information to an individual or } \\
\text { community group? }\end{array}$} & 16 & 10 \\
\hline & 13 & 8.1 \\
\hline $\begin{array}{l}\text { did you provide a private place for education, free from distraction and being } \\
\text { overheard by other patients? }\end{array}$ & 8 & 5 \\
\hline $\begin{array}{l}\text { did you use audiotapes to provide healthcare information to an individual or } \\
\text { community group? }\end{array}$ & 7 & 4.4 \\
\hline $\begin{array}{l}\text { did you use a health literacy screening tool to assess the health literacy skills of an } \\
\text { individual? }\end{array}$ & 5 & 3.1 \\
\hline 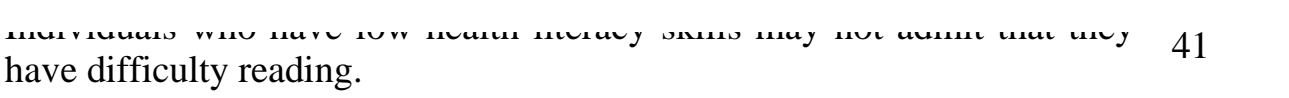 & 25.6 & 25 \\
\hline $\begin{array}{l}\text { The best way to ensure that a breast cancer prevention brochure is } \\
\text { culturally appropriate is to include community members in the design of } 39 \\
\text { the brochure. }\end{array}$ & 24.4 & 26 \\
\hline $\begin{array}{l}\text { Patients cope with low health literacy skills by pretending to read } 30 \\
\text { information given to them by healthcare providers. }\end{array}$ & 18.8 & 27 \\
\hline $\begin{array}{l}\text { The Test of Functional Health Literacy is used to assess the reading } 28 \\
\text { comprehension and numerical skills of an individual. }\end{array}$ & 17.5 & 28 \\
\hline $\begin{array}{l}\text { The nurse should limit the list to } 2-3 \text { items when listing side effects for a } 22 \\
\text { handout on chemotherapy the oncology }\end{array}$ & 13.8 & 29 \\
\hline
\end{tabular}

designing the brochure $(24.4 \%)$. Only less than 20 percent of senior nursing students correctly answered that patients cope with low health literacy skills by pretending to read information given to them by healthcare providers (18.8\%), that the Test of Functional Health Literacy is used to assess the reading comprehension and numerical skills of an individual (17.5\%) and that the nurse should limit the list to 2 to 3 items when listing side effects for a handout on chemotherapy (13.8\%).
Table 3 shows the percentage of "almost always" responses of senior nursing students' participation in learning activities related to health literacy and patient teaching. An "almost always" response indicates that the participant is actively involve or engage in health literacy and patient learning activities $75-100 \%$ of the time. It is shown that a little more than one third of senior nursing students claimed that health literacy was "almost always" emphasized in the nursing curriculum (35\%) and a little more than 
one fourth answered that they "almost always" assess what the patient already knows about his/her illness or injury prior to teaching (26.9\%). Few indicated that they "almost always" alter their teaching methods based upon experience in providing a conducive place for giving health information and in using technological devices and formal health literacy screening tools. Very few expressed that they "almost always" use computer software to

Table 4. Differences in Health Literacy Knowledge and Experience according to Sex and Grade in Health Education Course

\begin{tabular}{|c|c|c|c|c|}
\hline Category & Mean & SD & $\mathrm{t} / \mathrm{F}$ & $p$-value \\
\hline \multicolumn{5}{|l|}{ Knowledge } \\
\hline Sex & & & -1.612 & .109 \\
\hline Male & 12.48 & 2.36 & & \\
\hline Female & 13.33 & 2.52 & & \\
\hline Grade in Health Education Course & & & .693 & .598 \\
\hline Excellent - Outstanding & 12.57 & 2.51 & & \\
\hline Very Good & 13.55 & 2.04 & & \\
\hline Good & 13.35 & 2.53 & & \\
\hline Very Satisfactory & 13.10 & 2.56 & & \\
\hline Satisfactory - Passing & 12.67 & 2.87 & & \\
\hline \multicolumn{5}{|l|}{ Experience } \\
\hline Sex & & & -.472 & .637 \\
\hline Male & 2.47 & 0.37 & & \\
\hline Female & 2.50 & 0.42 & & \\
\hline Grade in Health Education Course & & & .480 & .751 \\
\hline Excellent - Outstanding & 2.67 & 0.47 & & \\
\hline Very Good & 2.54 & 0.43 & & \\
\hline Good & 2.47 & 0.42 & & \\
\hline Very Satisfactory & 2.53 & 0.38 & & \\
\hline Satisfactory - Passing & 2.41 & 0.41 & & \\
\hline
\end{tabular}

Table 5. Correlation between Health Literacy Knowledge and Health Literacy Experiencel

\begin{tabular}{lll}
\hline Variables & $r$ & $\mathrm{p}$-value \\
\hline Knowledge and Experience & -.046 & .563 \\
\hline$* \mathrm{p}<.05$ & &
\end{tabular}

the patient's health literacy status whether formally assessed or not (17.5\%), use written materials to provide healthcare information to an individual or community group (16.3\%), evaluate the use of illustrations in written healthcare materials before using them for patient teaching $(15.6 \%)$, assess the health literacy level of their patient (15\%), and evaluate the reading level of written healthcare materials before using them for patient teaching (11.9\%). In addition, senior nursing students had least provide healthcare information to an individual or community group (10.6\%), evaluate the cultural appropriateness of healthcare materials, including written handouts, videos, audiotapes, before using them for patient teaching (10\%), use videotapes to provide healthcare information to an individual or community group (8.1\%), provide a private place for education, free from distraction and being overheard by other patients (5\%), use audiotapes to provide healthcare information to an individual or community 
group (4.4\%) and use a health literacy screening tool to assess the health literacy skills of an individual $(3.1 \%)$.

Table 4 shows that t-test statistical result revealed no significant differences in health literacy knowledge $(\mathrm{t}=1.612 ; \mathrm{p}=.109)$ and health literacy experience $(\mathrm{t}=-.474 ; \mathrm{p}=.637)$ of senior nursing students grouped according to sex. Table 5 also shows that ANOVA statistical result revealed no significant differences in health literacy knowledge $(\mathrm{F}=.693 ; \mathrm{p}=.598)$ and health literacy experience $(\mathrm{F}=.480 ; \mathrm{p}=$ .751) of senior nursing students grouped according to grade in Health Education course.

Table 5 shows that the Pearson Correlation statistical result revealed health literacy knowledge was not significantly related to health literacy experience of senior nursing students $(r=-.046 ; \mathrm{p}=.563)$.

\section{DISCUSSION}

This research investigated the health literacy knowledge and experience of senior nursing students in a College of Nursing in the Philippines. It was demonstrated in this study that senior nursing students had a low level of knowledge on health literacy. This is not surprising to note. Most nursing schools include the patient education process in the nursing curricula, but do not specifically address low health literacy (Cornett, 2009). Nursing students from the Philippines are however, not the only students having a low level of health literacy knowledge. The finding of this study is congruent with earlier studies in the literature. Health literacy knowledge was low or lacking among senior nursing students in Louisiana, USA (Cormier, 2006; Cormier \& Kotrlik, 2009), Georgia (Williamson \& Chopak-Foss, 2015) South Africa (Mibei \& Daniels, 2019) and even among nurse practitioners (Cafiero, 2013). Nurses in Georgia (Knight, 2011) and Iran (Nesari, 2017) also had limited knowledge about health literacy in the areas of common or standard health literacy screening tools and guidelines for written healthcare materials. Likewise, emergency nurses in the USA correctly answered only $62 \%$ of the knowledge questions about health literacy (Kennard, 2017). Furthermore, similar to the findings of this study, a qualitative research noted that nursing students do not employ standardized tools to assess the health literacy of patients (Shieh et al., 2013).

It is significant to note that senior nursing students in this study had moderate health literacy experience. This may be attributed to their experiences to the different clinical areas and community settings since they are already in their fourth-year in nursing school. Related Learning Experiences serve as sources of authentic learning experiences for students (Oducado \& Penuela, 2014). Nursing students were able to experience providing health education to their patients, but they might not have utilized some of the learning activities and strategies related to health literacy. Nursing students may have used informal ways of assessing health literacy, such as directly asking their patients if they have difficulty in reading or understanding health information. Despite the gaps in knowledge, the findings of this study imply that the undergraduate nursing program in the Philippines is providing sufficient and relevant Related Learning Experiences for students to engage in various patient education and learning activities.

Meanwhile, senior nursing students in this study expressed the least extent of health literacy experience in providing a private place for education, free from distraction, and being overheard by other patients. Nursing students in this study generally had their clinical placements in public hospitals and were assigned in the wards wherein there is a large volume of patients. Providing a private place for health education in the ward setting is merely possible. In addition, the use of formal health literacy screening tools such the Test for Functional Health Literacy in Adults, Rapid Estimate of Adult Literacy in Medicine, and Fry Method may not have been given emphasis in the nursing curriculum. Henceforth, senior nursing students may lack knowledge and experience in the use of these formal screening tools. These tools, while known and are being used in other countries, were less likely introduced among nursing students in the Philippines. These health literacy screening tools may need to be assessed first for cultural acceptability or equivalence within the Philippine setting. It was earlier found that nursing students expressed inadequate 
theoretical preparation for health teaching as a barrier to health literacy (Zanchetta et al., 2013).

Moreover, senior nursing students in this study lack experience in employing technologies in providing health information. Although nursing students were exposed in the community setting wherein they have experienced providing health education through powerpoint and video presentations, it was only limited for a few weeks. It might have been difficult for the students to use technological devices in the ward setting.

The finding on the extent of health literacy experience of this study is not supportive of the result of earlier studies conducted elsewhere. Nursing students in this study reported more health literacy experiences compared to the samples of previous investigations. Health literacy experience was found to be low among senior nursing students in Louisiana, USA (Cormier, 2006; Cormier \& Kotrlik, 2009) and there was lack of health literacy experience among senior nursing students in Georgia (Williamson \& Chopak-Foss, 2015). Moreover, limited health literacy experience was also noted among fourth-year nursing students in Western Cape, South Africa (Mibei \& Daniels, 2019).

Furthermore, differences in health literacy knowledge and experience according to sex and grade in Health Education course were not appreciated in this study. Nursing students' health literacy knowledge and experience do not vary according to their sex and their grade in Health Education course. Senior nursing students had taken up the Health Education course in their second year in nursing school. It is expected that students are taught of the same course content. Nursing students may have the same knowledge and understanding of health literacy. Moreover, senior nursing students were also given or exposed to almost similar Related Learning Experiences and situations showing no variation in their health literacy experience as revealed in this study.

Nevertheless, the findings on this aspect of the study are not the same as with the results of earlier scholars. The survey of Cormier (2006) disclosed that GPA predicted health literacy knowledge. Another study revealed that nursing students with higher grades were more likely to have higher scores on health literacy (Zhang et al., 2016). Correspondingly, students having more health education-related subjects were found to have higher health literacy competency (Sukys et al., 2017). As to sex, similar to the report in this study, a study found that gender was not significantly related to health literacy knowledge (Potter, 2017). On the contrary, Korean adult women were noted to have a higher level of health literacy than men (Lee et al., 2015).

This study also demonstrated that senior nursing students' health literacy knowledge was not associated with health literacy experience. In contrast, prior studies indicated low to weak negative association between nursing students' knowledge and experience with health literacy (Cormier, 2006; Nesari, 2017). In this study, however nursing students' level of health literacy knowledge does not affect their extent of health literacy experience. Senior nursing students were moderately engaged in health literacy activities, even if they lack sufficient knowledge about health literacy. This could be attributed to their exposure to the different clinical areas and community settings where they had been given opportunities to engage themselves in various health education and patient learning activities. A prior study disclosed that experiences of students to address health literacy described themes such as helping patients understand (Scheckel et al., 2010). Moreover, Health Education is a part of the $11 \mathrm{Key}$ Areas of Responsibility of nurses in the Philippines and is considered a primary duty of every nurse (Belo-Delariarte et al., 2018). Nursing students are, therefore expected or even required to give health education to their clients.

Finally, this study is limited to a single college, and the survey was conducted at a particular point in time. Inferring causality between study variables was difficult, and extrapolating results to other nursing students may not be possible. Moreover, while Cormier's HL-KES was evaluated by experts to be culturally acceptable, it was with the intention of the researchers to specifically use the HL-KES. This allowed the researchers to compare the results of the present investigation with similar studies using the tool. However, the researchers suggest that a more valid and reliable instrument 
may be developed and used in future studies among Filipino samples. Nonetheless, this research contributed to the body of knowledge in the literature and addressed the limited research in the Philippines on the topic of health literacy in nursing education.

\section{CONCLUSIONS}

Similar to studies conducted abroad, senior nursing students in the Philippines have limited health literacy knowledge. Despite the knowledge gaps in terms of guidelines in written healthcare information and health literacy screening likewise the limited usage of formal health literacy screening tools and technological devices when providing healthcare information, senior nursing students are provided with reasonable and relevant health literacy experiences in the undergraduate nursing program. While health literacy topic may not have been given an in-depth discussion in the health education course, nursing students are always required and expected to provide health education to their clients whether in the clinical or community setting. Nursing students know that giving health education is a primary responsibility of every nurse and it is one of the 11 Key Areas of Responsibility. It is strongly recommended that the health literacy topic must be given greater emphasis in the undergraduate nursing curriculum.

\section{REFERENCES}

Agency for Healthcare Research and Quality. (2016). Health literacy measurement tools (Revised). Retrieved from http://www.ahrq.gov/professionals/quali ty-patient-safety/qualityresources/tools/literacy/index.html

Agosto, H.G.C., Briones, M.V.A., \& Palatino, M.C. (2018). Correlates of health literacy among Filipinos aged 50-70 years old belonging to low-income families in a selected community. Acta Medica Philippina, 52(3), 239-244. Retrieved from

https://www.actamedicaphilippina.org/a rticle/5148-correlates-of-health-literacyamong-filipinos-aged-50-70-years-old- belonging-to-low-income-families-in-aselected-community

Belo-Delariarte, R.G.B., Oducado, R.M.F., \& Penuela, A.C. (2018). Terminal assessment of core nursing knowledge in a state university. Asia Pacific Journal of Multidisciplinary Research, (6)2, 10-17. Available at http://www.apjmr.com/wpcontent/uploads/2018/06/APJMR2018.6.2.2.02.pdf

Borrero, J.G. (2016). A study of the effect of a Health Literacy Module (HeLM) on the health literacy knowledge, attitudes and skills of pre-licensure baccalaureate nursing students. Journal of Nursing \& Care. https://doi.org/10.4172/21671168.C1.032

Budhathoki, S.S., Pokharel, P.K., Jha, N., Moselen, E., Dixon, R., Bhattachan, M., \& Osborne, R.H. (2019). Health literacy of future healthcare professionals: A cross-sectional study among health sciences students in Nepal. International Health, (11)1, 15-23. https://doi.org/10.1093/inthealth/ihy090

Cafiero, M. (2013). Nurse practitioners' knowledge, experience, and intention to use health literacy strategies in clinical practice, Journal of Health Communication, 18:sup1, 70-81, https://doi.org/10.1080/10810730.2013. 825665

Centers for Disease Control and Prevention. (2016). Infographic: Health literacy. Available at https://www.cdc.gov/cpr/infographics/h ealthliteracy.htm

Clark, K.M. (2009). Health literacy: the current state of practice among respiratory therapists.

(Doctoral Dissertation). University of North Carolina. Available at http://libres.uncg.edu/ir/uncc/f/Clark_un cc_0694D_10050.pdf

Cormier, C.M. (2006). Health literacy: the knowledge and experiences of senior level baccalaureate nursing students (Doctoral Dissertation). Louisiana State University and Agricultural and Mechanical College. Available 
https://digitalcommons.lsu.edu/gradscho ol_dissertations/4027

Cormier, C.M., \& Kotrlik, J.W. (2009). Health literacy knowledge and experience of senior baccalaureate students. Journal of Nursing Education, 48, 237-248. doi: 10.9999/01484834-20090416-02

Cornett, S. (2009). Assessing and addressing health literacy. OJIN: The Online Journal of Issues in Nursing, 14(3), Manuscript 2. doi: 10.3912/OJIN.Vol14No03Man02

Griffey, R.T., Kennedy, S.K., D’Agostino McGowan, L., Goodman, M., \& Kaphingst, K. A. (2014). Is low health literacy associated with increased emergency department utilization and recidivism? Academic Emergency Medicine, 21(10), 1109-1115. https://doi.org/10.1111/acem.12476

Institute of Medicine (US). (2004). Health literacy: A prescription to end confusion. Washington (DC): National Academies Press (US). Available at https://www.ncbi.nlm.nih.gov/books/NB K216035/

Kennard, D.K. (2016). Health literacy concepts in nursing education. Nurse Education Perspectives, 37(2), 118-119. doi: 10.5480/14-1350

Kennard, D. (2017). Emergency room nurses knowledge of and experience with health literacy and their patient teaching methods (Doctoral Dissertation). Seton Hall University. Available at https://scholarship.shu.edu/dissertations/ 2270

Knight, G. (2011). An evaluation of the health literacy knowledge and experience of registered nurses in Georgia (Doctoral Dissertation). Auburn University. Available at http://etd.auburn.edu/bitstream/handle/1 0415/2460/Glenda_Knight_Dissertation _Dec_2010_2.pdf?sequence $=2 \&$ isAllow ed $=\mathrm{y}$

Lee, H.Y, Lee, J., \& Kim, N.K. (2015). Gender differences in health literacy among Korean adults: Do women have a higher level of health literacy than men?
American Journal of Men's Health, 9(5), 370-379. https://doi.org/10.1177/1557988314545 485

Macabasco-O'Connell, A., \& Fry-Bowers, E.K. (2011). Knowledge and perceptions of health literacy among nursing professionals. Journal of Health Communication, 16(S3), 295-307. https://doi.org/10.1080/10810730.2011. 604389

McCleary-Jones, V. (2012). Assessing nursing students' knowledge of health literacy. Nurse Educator, 37(5), 214-217. doi: 10.1097/NNE.0b013e318262ead3

Mibei, F. \& Daniels, F. (2019). Health literacy knowledge and experiences of nursing students at a South African University. African Journal of Nursing and Midwifery, 21(1). https://doi.org/10.25159/25205293/3205

Mullan, J., Burns, P., Weston, K., McLennan, P., Rich, W., Crowther, S., Mansfield, K., Dixon, R., Moselen, E., \& Osborne, R.H. (2017). Health literacy amongst health professional university students: A study using the health literacy questionnaire. Education Sciences, 7(54). https://doi.org/10.3390/educsci7020054

Nesari, M. (2017). Health literacy: knowledge and experiences of Iranian registered nurses (Doctoral Dissertation). University of Alberta. Available at https://era.library.ualberta.ca/items/5b60 1500-e7f7-4288-a7ddc0f09c702196/view/d0b589fe-26dd$44 \mathrm{fa}-\mathrm{a} 3 \mathrm{a} 5$ acdf74a06610/Nesari_Maryam_201703 _PhD_PdF.pdf

Oducado, R.M.F., \& Penuela, A.C. (2014). Predictors of academic performance in professional nursing courses in a private nursing school in Kalibo, Aklan, Philippines. Asia Pacific Journal of Education, Arts and Sciences, 1(5): 21$28 . \quad$ Available at http://apjeas.apjmr.com/wpcontent/uploads/2014/11/APJEAS2014-1-079.pdf 
Philippine Health Research Ethics Board. (2017). National ethical guidelines for health and health-related research 2017. Retrieved from

Potter, J. (2017). Health literacy of nursing students and their awareness of patient literacy needs (Doctoral Dissertation). Walden University. Available at https://scholarworks.waldenu.edu/cgi/vi ewcontent.cgi?referer=https://www.goo gle.com $/ \&$ httpsredir $=1 \&$ article $=5350 \& \mathrm{c}$ ontext=dissertations

Sand-Jecklin, K., Murray, B., Summers, B., \& Watson, J. (2010). Educating nursing students about health literacy: From the classroom to the patient bedside. OJIN: The Online Journal of Issues in Nursing, 15(3). doi: 10.3912/OJIN.Vol15No03PPT02

Scheckel, M., Emery, N., \& Nosek, C. (2010). Addressing health literacy: the experiences of undergraduate nursing students. Journal of Clinical Nursing, 19(5-6):

794-802.

https://doi.org/10.1111/j.1365-

2702.2009.02991.x

Shieh, C., Belcher, A.E., \& Habermann, B. (2013). Experiences of nursing students in caring for patients with behaviors suggestive of low health literacy: A qualitative analysis. Journal of Nursing Education and Practice, 3(2), 75-85. http://dx.doi.org/10.5430/jnep.v3n2p75

Sukys, S., Cesnaitiene, V.J., \& Ossowsky, Z.M. (2017). Is health education at university associated with students' health literacy? Evidence from cross-sectional study applying HLS-EU-Q. BioMed Research International, Article ID 8516843. https://doi.org/10.1155/2017/8516843

Sullivan, S. (2015). An evaluation of health literacy education: effects on cultural competence, knowledge and attitudes of associate degree nursing (Doctoral Capstone Project). Capella University. Available at https://sigma.nursingrepository.org/bitst ream/handle/10755/556956/Lisa_M_Sul
livan_Manuscript_7_20_2015.pdf?seque nce $=8$

Torres, R., \& Nichols, J. (2014). Health literacy knowledge and experiences of associate degree nursing students: A pedagogical study1. Teaching and Learning in Nursing, $\quad$ 9(2): $\quad$ 84-92. https://doi.org/10.1016/j.teln.2013.11.00 3

United States Department of Health and Human Services. (2000). Healthy People 2010: Understanding and improving health. 2nd ed. Washington DC: U.S. Government Printing Office. Retrieved from http://health.gov/healthypeople/

Williamson, S.S., \& Chopak-Foss, J. (2015). Differences in health literacy knowledge and experiences among senior nursing students. Journal of Georgia Public Health Association, 5 (2): 184-190. Available

at https://digitalcommons.georgiasouthern. edu/commhealth-facpubs/126

World Medical Association. (2001). World Medical Association Declaration of Helsinki. Ethical principles for medical research involving human subjects. Bulletin of the World Health Organization, 79(4), 373-374. Retrieved from https://www.who.int/bulletin/archives/7 9\%284\%29373.pdf

Zanchetta, M., Taher, Y., Fredericks, S., Waddell, J., Fine, C., \& Sales, R. (2013). Undergraduate nursing students integrating health literacy in clinical settings. Nurse Education Today, 33(9), 1026-1033. doi: 10.1016/j.nedt.2012.05.008

Zhang, Y., Zhang, F., Hu, P., Huang, W., Lu, L.,Bai, R., \& Zhao, Y. (2016). Exploring health literacy in nursing students of Chongqing, China: a cross-sectional survey using the health literacy questionnaire. The Lancet, 388(S99). https://doi.org/10.1016/S01406736(16)32026-8 